\title{
THE LABORATORY ASPECTS OF SEXUAL CRIME*
}

\author{
BY \\ H. S. HOLDEN \\ Director of the Metropolitan Police Forensic Science Laboratory
}

There are two groups of offences in this country in which the police have normally sought the help of the medical profession, namely, the various crimes involving violence- such as murder, attempted murder, grievous bodily harm, and the likeand the whole range of sexual offences.

Since the establishment during the last decade of government-sponsored forensic science laboratories, help from these institutions has also been looked for ; and it is obviously desirable to have close and efficient co-operation between the members of the medical profession and the staffs of the forensic science laboratories.

\section{Divisions of Sexual Crime}

For the purpose of this paper, sexual crimes may be divided into three fairly well-defined groups namely : (1) indecent assaults of varying degrees of gravity ; (2) rape, attempted rape, and carnal knowledge ; (3) sodomy, bestiality, and gross indecency with males.

Indecent Assault.-Of these, the less serious forms of indecent assault are the most difficult to establish. The tearful or excited child's complaint to its mother, and the demonstration, from an examination of the clothing of suspect and victim, of close association are frequently all that is available to go upon. The child's private parts should of course be examined by some competent medical practitioner although the findings are usually negative. It should be borne in mind that in most cases of assault of this type the children come from the poorer class of home, where the daily tub is not the rule. Such children may show signs of redness and irritation of the pudenda which, whilst suggesting interference, may be due, as in an example which passed through my hands, to threadworm infection. In this particular instance a swab from the labia revealed a living threadworm and large numbers of ova.

The grosser type of indecent assault takes the form of using the child as an agent of masturbation by indulging in intercrural coitus.

A typical example of an offence of this character is provided by a case which came from a Lincolnshire seaside town. Three small girls, accompanied by a

*An address to the Medical Society for the Study of Venereal Diseases, February 26, 1948. rough-haired terrier, were approached by a strange man who gave them sweets and took them on to the sandhills where he indecently assaulted all three. Their story, when they returned home, led the parents to communicate with the police, and their clothing was put aside for examination. By a lucky chance one of the children, out walking with her mother, saw the man on the sea front the next day. The police were informed, and the man was interviewed and later charged with the offence. Examination of the children's clothing showed seminal stains on the inner surface of the knickers of all three, whilst the clothing of the accused not only showed seminal stains on the outside of the trousers but dog hairs which matched those of the rough-haired terrier on his trousers, scarf, and overcoat. Most damning evidence of all was provided by a number of coloured wool fibres adhering to his trouser flies which agreed in every detail with the wool fibres of the knitted frock worn by one of the children. The children had been medically examined, and it was reported that the labia of one of them were red and inflamed. It subsequently transpired, however, that this condition was due to the action of an over-zealous mother who had dabbed the child's private parts with strong disinfectant to guard against possible infection.

In cases such as the one just described there was abundant evidence leading to conviction, and frequently in cases of rape the evidence, provided the complaint is a genuine one, is unequivocal, especially where any degree of violence has been used. This evidence usually takes the form of more or less severe bruising or more serious injury, of torn and damaged clothing, and, of course, of seminal material in the vagina where complete intercourse has occurred. Where the victim is a virgin there is the additional evidence yielded by the blood stains from the ruptured hymen. An examination of the suspect's clothing in such cases usually reveals seminal stains associated with blood and traces of vaginal debris on and about the trouser flies and on the front lap of the shirt.

It should not, however, be lost sight of that, apart from injury and other evidences of ill treatment and rough usage, the finding of semen, bloodstains, and vaginal debris provides proof of sexual intercourse only, and not of rape. There is however a strong presumption of rape where the female is a child of tender years. A case of this kind from the city of Nottingham was remarkable for the variety of material which proved to have high evidential value. 
A child seven years of age was enticed away from the neighbourhood of her home by a stranger, who took her into a nearby wood and there raped her, inflicting very serious injury. Late that night, after intensive police search, the child was discovered in a state of collapse, dirty, and dishevelled, with soil and plant fragments of various kinds on her hair, footwear, and clothing.

The soil and plant material were carefully collected and preserved, and proved at a later stage to show close agreement with samples from the " scene" when this was located. Among the discoveries at the scene were a blood-stained beech leaf and a soiled length of bandage showing traces of ointment. The latter proved of considerable importance as establishing the presence of the child in that part of the wood " beyond all reasonable doubt," since the mother was able to state that she had bandaged a cut on the child's hand. The traces of ointment on the bandage were similar to those used by the mother, but the matter was clinched by the fact that both the bandage from the scene and the rest of the roll still in the child's home showed an identical flaw in the weave. A suspect was located in a common lodging house, and examination of his clothing revealed blood and seminal stains together with several fine head hairs which matched those of the injured girl. In addition plant fragments, seeds, and soil agreeing with that from the wood were present on his trousers; and in a cake of soil adhering to the arch of one shoe was a portion of a leaf showing a trace of human blood. All the bloodstains on the suspect's clothing were of human origin and belonged to the same group as that of the child. The blood of the accused was not available for grouping. The child was found to have been infected with gonorrhœa, and when the prisoner was examined it was established that he was actually under treatment for acute gonorrhœa at the time of the offence. It transpired later that he believed that intercourse with a virgin would clear him of infection.

Whilst examples such as the one just described are relatively straightforward, once the case material has been fully considered, it should be borne in mind that ill-founded or deliberately false and malicious accusations of rape are met with from time to time. An itch for the limelight, attempts to cover up an act of infidelity, an exceptionally vivid imagination, or deliberate malice and vindictiveness following the rejection of invitations to sexual intimacy, all may result in allegations of rape ; and it is because examples of this kind are familiar to all experienced forensic pathologists that in every textbook of forensic medicine stress is laid on the detailed study of the available data for corroborative evidence.

Carnal Knowledge.-Carnal knowledge cases normally offer much less difficulty. Pregnancy may result, and apart from this contingency the corroboration of the girl's story by physical examination and proof of close association with the accused are the only aspects which need concern us.
Sodomy and Bestiality. - Of the third group of sexual offences the two most interesting from the laboratory angle are sodomy and bestiality. Sodomy is an offence in which careful examination of both the active and the passive offender by a doctor is essential. I need not dilate on the findings likely to result from such an examination, but in the laboratory examination the chief things to be looked for are :

(a) Passive Partner.-The presence of semen associated with traces of fæces, and frequently with traces of some lubricant such as petroleum jelly, in the crutch of the underpants or trousers, or the inner surface of the back of the shirt: the presence of semen in the anal swab where this can be taken soon after the commission of the offence; the presence of foreign pubic hairs.

(b) Active Partner.-Traces of semen, excrement, and lubricant on the penis, on and near the trouser flies, and on the front lap of the shirt.

Bestiality, unlike sodomy, is in my experience predominantly a rural as distinct from an urban offence, and in its commíssion I have known instances of the use of most of the domestic animals including cows, horses, sheep, pigs, and, less frequently, dogs. The fact that the offender is generally, by virtue of his calling, associated with various types of domestic animal, renders great caution necessary in assessing the significance of animal hair and traces of dung on the clothing. In my view, if it is to have high evidential value, animal hair on the clothing of a suspect should not only be a homogeneous sample but should occur on parts of the clothing upon which they would not normally be found. Thus animal hairs found on and inside the trouser flies and on the front lap of the shirt, associated with traces of semen, animal excrement, and possibly vaginal exudates, would constitute significant findings. The presence of human semen in vaginal swabs from the animal involved would also constitute important corroborative evidence.

Sexual Background of Crimes of Violence.-One final point is perhaps worthy of mention, and that is that a considerable proportion of crimes of violence, such as murder and attempted murder, have a sexual background.

\section{Conclusion}

From the above it will be seen that close collaboration between the doctor, the scientist, and the investigating officer, is important in all enquiries into the various types of sexual offence, whether real or imaginary. 